\title{
Desigualdades urbanas e desigualdades sociais nas metrópoles brasileiras
}

MARGELO GOMES RIBEIRO

\section{Resumo}

Este trabalho objetiva analisar as desigualdades urbanas das principais metrópoles do país por meio do Índice de Bem-Estar Urbano (IBEU), elaborado pelo Observatório das Metrópoles. Como a análise do IBEU revela desigualdades de bem-estar urbano no interior das metrópoles, procura-se relacionar essas desigualdades urbanas com o perfil socioeconômico das pessoas que compõem as diferentes áreas das metrópoles. É observado nítida correspondência entre as desigualdades urbanas e as desigualdades sociais, o que nos leva à reflexão de seus mecanismos explicativos, por meio dos processos de diferenciação, segmentação e segregação socioespaciais e também por meio do processo de causação circular da distribuição dos recursos coletivos urbanos.

Palavras-chave: Bem-estar Urbano. Desigualdades. Segregação Socioespacial. Metrópoles.

${ }^{*}$ Universidade Federal do Rio de Janeiro (Brasil). 


\section{Urban inequalities and social inequalities in Brazilian metropolises}

\section{Abstract}

This paper aims to analyze the urban inequalities of the main cities of the country through Welfare Urban Index (IBEU), prepared by the Observatory of the Metropolises. As the analysis of IBEU reveal urban welfare inequities within cities, it seeks to relate these urban inequalities with the socio-economic profile of the people that make up the different areas of the metropolis. It is observed clear correspondence between urban inequalities and social inequalities, which leads us to reflect their explanatory mechanisms, through the processes of socio-spatial differentiation, segmentation and segregation and also through the circular causation process of distribution of urban public resources.

Keywords: Urban Welfare. Inequalities. Metropolitan Area. Socio-spatial Segregation.

\section{Introdução}

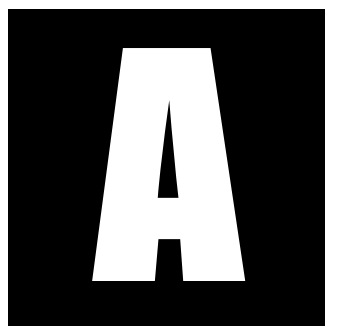

florou de maneira vertiginosa no debate público nacional dos anos 1960/1970 o que se convencionou chamar de questão urbana. O debate que girou em torno dessa problemática, que envolveu diversos setores e segmentos da sociedade, com alcance mais ou menos limitado no Estado, revelava de modo surpreendente as consequências das opções de desenvolvimento econômico adotadas no país, principalmente a partir dos anos de 1950, no que ficou configurado como desenvolvimentismo associado $^{1}$ (lanni, 1971). Por um lado, por meio da questão urbana se

\footnotetext{
${ }^{1}$ Octavio lanni, ao discutir as opções de políticas econômicas governamentais por meio da relação entre Estado e economia, afirma que "A história da política econômica governamental
} 
procurava compreender a especificidade da urbanização brasileira - ou dos países da América Latina -, por ter apresentado descompasso em relação ao crescimento econômico quando este passou a ser impulsionado pelo processo de industrialização, diferente das experiências dos países de industrialização originária, onde houve maior correspondência (Castells, 1973; Quijano, 1973; Singer, 2012). Por outro lado, por meio dessa problemática se procurava também compreender o modo como os principais aglomerados urbanos do país se conformavam, ao incorporar em sua morfologia social, a própria questão social brasileira. Havia, nesta perspectiva analítica, uma nítida conexão entre a frágil inserção (quando não a sua ausência) no mercado de trabalho de parcela significativa das pessoas que passavam a morar nos centros urbanos e as condições precárias de moradia, manifestadas pelos alugueis de cômodos, cortiços, favelas ou mesmo pela autoconstrução nas áreas periféricas das grandes cidades ou em torno delas (Kowarick, 1993; Maricato, 1979). Associado à precariedade da moradia estavam a ausência de infraestrutura e serviços coletivos adequados, como pavimentação, saneamento básico, atendimento de água e energia elétrica, além do problema do transporte público devido às grandes distâncias que separavam o lugar da reprodução social e o lugar de concentração dos postos de trabalho.

Muitas foram as interpretações da questão urbana brasileira que procuravam lançar luz sobre os fenômenos sociais, econômicos ou políticos que efetivavam a construção de cidades com configuração socioespacial mencionada, traduzida principalmente pelo modelo de organização terri-

brasileira, desde 1930, indica que esta oscilou entre duas tendências principais. Uma dessas tendências, que pode ser denominada estratégia de desenvolvimento nacionalista, predominou nos anos 1930-1945, 1951-1954 e 1961-1964. (...) A outra, que pode ser chamada de estratégia de desenvolvimento associado, predominou nos anos 1946-1950, 1955-1960 e desde 1964 em diante. Ela continha, como pressuposto implícito e explícito, o projeto de um capitalismo associado como única alternativa para o progresso econômico e social". (grifo conforme original) 
torial que se convencionou chamar de centro-periferia, que para além da expressão geográfica dos grupos sociais residentes da cidade eram também expressão das desigualdades sociais e das desigualdades urbanas (Kowarick, 1993; Vetter et. al., 1981; Oliveira, 1982). As interpretações de modo geral procuraram revelar que era por meio do relacionamento entre a classe (ou frações da classe) dominante e o Estado que as desigualdades urbanas e, portanto, a questão urbana se manifestava nas grandes cidades do país.

Lúcio Kowarick (1993), por meio do conceito de espoliação urbana, denunciava o modo como o Estado contribuía para o que chamou de movimento contraditório da acumulação do capital, tanto como suporte de infraestrutura para expansão industrial como por meio da manutenção da ordem social. Segundo esse o autor, a espoliação urbana é designada como “o somatório de extorsões que se operam através da inexistência ou precariedade de serviços de consumo coletivo, apresentados como socialmente necessários em relação aos níveis de subsistência, e que agudizam ainda mais a dilapidação realizada no âmbito das relações de trabalho" (p. 62).

Vetter et. al. (1981), a partir do conceito de Renda Real² de David Harvey (1973), procuraram compreender os mecanismos que fazem com que o Estado favoreça os grupos sociais de mais alto rendimento com os recursos coletivos urbanos em detrimento dos grupos sociais de menor rendimento por meio do conceito de causação circular, em que podemos resumir como "as ações do Estado em um dado período acabam tendo impactos sobre a segregação residencial que, por sua vez, tem implicações importantes na futura distribuição dos benefícios líquidos das ações do Estado". Isso ocorre porque os grupos beneficiados pela ação do Estado aumentam sua renda real, pela valorização que ocorre dado o mecanismo

\footnotetext{
${ }^{2}$ A Renda Real de formulação de David Harvey (1973) é designada por Vetter et. al. (1981) como sendo o controle sobre os recursos escassos da sociedade dos diferentes grupos socioeconômicos. Ela pode também ser compreendida pela renda monetária somada à renda não-monetária, advinda dos recursos coletivos urbanos.
} 
do sistema de preço do solo, o que impede a entrada de grupos sociais de menor rendimento nos espaços onde esses recursos foram direcionados, tornando os grupos que aí residem segregados em relação aos demais, o que aumenta ainda mais o seu poder de reivindicação frente ao Estado.

Também é digno de nota, a interpretação realizada por Francisco de Oliveira, no seu famoso texto intitulado "O Estado e o urbano no Brasil" (1982). Nesse trabalho, Oliveira procura demonstrar a centralidade que o urbano sempre apresentou no processo de acumulação do capital desde o momento em que o Brasil ainda era colônia portuguesa. Procura demonstrar as mudanças que o papel do urbano sofre dado o início do processo de industrialização e, principalmente, decorrente do momento em que a industrialização se torna intensiva com maior entrada de capital estrangeiro, mas também com a incorporação de novas formas de organização das empresas, o que faz surgir a denominada classe média ou alta classe média: grupos sociais constituídos por altos executivos das empresas multinacionais, diretores, gerentes, variados tipos de profissionais, que também se configuram no aparelho do Estado, dotados de poder econômico e político. A partir desse momento, que se manifesta exatamente quando se emerge a questão urbana no país, o urbano passa a ser compreendido a partir do atendimento do Estado aos interesses da classe média, em detrimento das classes populares desprovidas do poder de reivindicação.

Decorrente do processo histórico apresentado, a questão que se coloca é a de saber como na atualidade se manifestam as desigualdades urbanas nas principais metrópoles do país. No intuito de buscar resposta a essa questão, o Observatório das Metrópoles elaborou um Índice de Bem-Estar Urbano (IBEU) para a principais metrópoles brasileiras, a partir dos dados do censo demográfico do IBGE, de 2010, pois esse levantamento possibilita a análise intraurbana do conjunto de municípios do país (Ribeiro; Ribeiro, 2013a). 
A concepção de bem-estar urbano que fundamenta o referido Índice decorre da compreensão daquilo que a cidade deve propiciar às pessoas em termos de condições materiais de vida, a serem providas e utilizadas de forma coletiva. Tal dimensão está relacionada com as condições coletivas de vida promovidas pelo ambiente construído da cidade, nas escalas da habitação e da sua vizinhança próxima, e pelos equipamentos e serviços urbanos. Nessa concepção de bem-estar urbano, o que importa são as condições de reprodução social que se constituem e se realizam coletivamente, mesmo que em práticas ou experiências individuais.

O IBEU foi calculado para os 15 maiores aglomerados urbanos do país, sendo considerados como as principais metrópoles brasileiras, identificadas em estudo realizado pelo Observatório das Metrópoles (Observatório, 2005), por exercerem funções de direção, comando e coordenação dos fluxos econômicos, compreendidas por São Paulo, Rio de Janeiro, Brasília, Belo Horizonte, Curitiba, Porto Alegre, Salvador, Recife, Fortaleza, Manaus, Belém, Goiânia, Campinas, Florianópolis e Grande Vitória.

Esse índice contém cinco dimensões: mobilidade urbana; condições ambientais urbanas; condições habitacionais urbanas; atendimento de serviços coletivos urbanos; infraestrutura urbana. E cada uma dessas dimensões é constituída por um conjunto de indicadores, construídos a partir de dados do censo demográfico do Instituto Brasileiro de Geografia e Estatística (IBGE) de 2010³.

Este trabalho está organizado em mais quatro seções, além desta introdução. Na segunda seção, serão analisadas as desigualdades de bem-estar urbano das principais metrópoles do país em conjunto e comparativamente. Na terceira seção, serão relacionadas as desigualdades urbanas, por meio do IBEU, com o perfil socioeconômico dos grupos sociais das

${ }^{3}$ Para ver o detalhamento das variáveis existentes em cada uma das dimensões do IBEU, bem como todo o procedimento metodológico da construção do índice, consultar Ribeiro; Ribeiro (2013a). 
metrópoles. Na quarta seção, procuramos buscar explicação para os relacionamentos observados entre o IBEU e o perfil socioeconômico. E nas considerações finais, procuramos sumarizar os resultados encontrados e apresentar desdobramentos possíveis da análise realizada.

\section{IBEU das principais Metrópoles Brasileiras}

Passadas mais de três décadas do debate acerca da questão urbana brasileira, que tiveram como máxima expressão as desigualdades urbanas das principais metrópoles do país, especialmente pela ausência de serviços e infraestrutura em suas periferias, podemos observar ainda hoje a existência de contrastes urbanos quando as analisamos no espaço intrametropolitano, configurando situações muito díspares dentro de uma mesma metrópole referente ao acesso aos recursos coletivos necessários à reprodução social nas grandes cidades, o que caracteriza as diferentes condições de bem-estar urbano. Apesar de não apresentar a mesma situação observada nas décadas de 1960 e 1970, pois houve mudanças econômicas, sociais e políticas significativas no país ao longo das últimas décadas, as desigualdades urbanas ainda são uma marca presente das principais metrópoles brasileiras.

É ilustrativo no gráfico 1 que 40,8\% das pessoas residentes das principais metrópoles do país moram em espaços cujas condições urbanas são consideradas adequadas ${ }^{4}$, ao considerar a soma das pessoas que es-

\footnotetext{
${ }^{4} \mathrm{~A}$ designação de condições adequadas, médias ou inadequadas de bem-estar urbano é definida, neste trabalho, de modo arbitrário pelo autor, tendo como parâmetro exclusivamente a indicação do índice, que varia numa escala de zero a um. Essa é uma opção para apresentação dos resultados observados, tendo em vista o objetivo de demonstrar as desigualdades existentes nas metrópoles, na medida em que não encontramos suporte teórico para avaliar o grau em que as condições urbanas se apresentam como adequada ou inadequada. Do mesmo modo, a classificação de muito alta, alta, média, baixa e muito baixa condições de bem-estar urbano.
} 
tão em espaços de alto $(32,2 \%)$ e muito alto $(8,6 \%)$ bem-estar urbano. Há também 35,5\% de pessoas que estão em condições médias e 23,7\% de pessoas que estão em condições inadequadas de bem-estar urbano, ao considerar aquelas que estão em espaços de baixo $(22,6 \%)$ e muito baixo $(1,1 \%)$ bem-estar urbano. Isto é, há mais pessoas em condições adequadas de bem-estar urbano que pessoas em condições inadequadas, ao contrário do que se verificava em décadas anteriores quando o contingente de pessoas em condições inadequadas era mais expressivo.

Todavia, mesmo considerando a melhoria dessas condições ao longo das últimas décadas, praticamente um quarto das pessoas ainda sofre com a precariedade das condições urbanas nas principais metrópoles do país. Algo nada desprezível quando se considera em termos absolutos, pois corresponde a um contingente de 16.643.181 de pessoas. Se se considerar que o Estado do Rio de Janeiro possuía, em 2010, em torno de 16 milhões de pessoas - terceiro estado mais populoso do país -, podemos considerar que há um contingente maior que a população desse Estado em condições precárias de bem-estar urbano, porém espalhadas pelo conjunto das 15 principais metrópoles do país. 
Gráfico 1. Nível do IBEU das 15 principais regiões metropolitas do Brasil - 2010

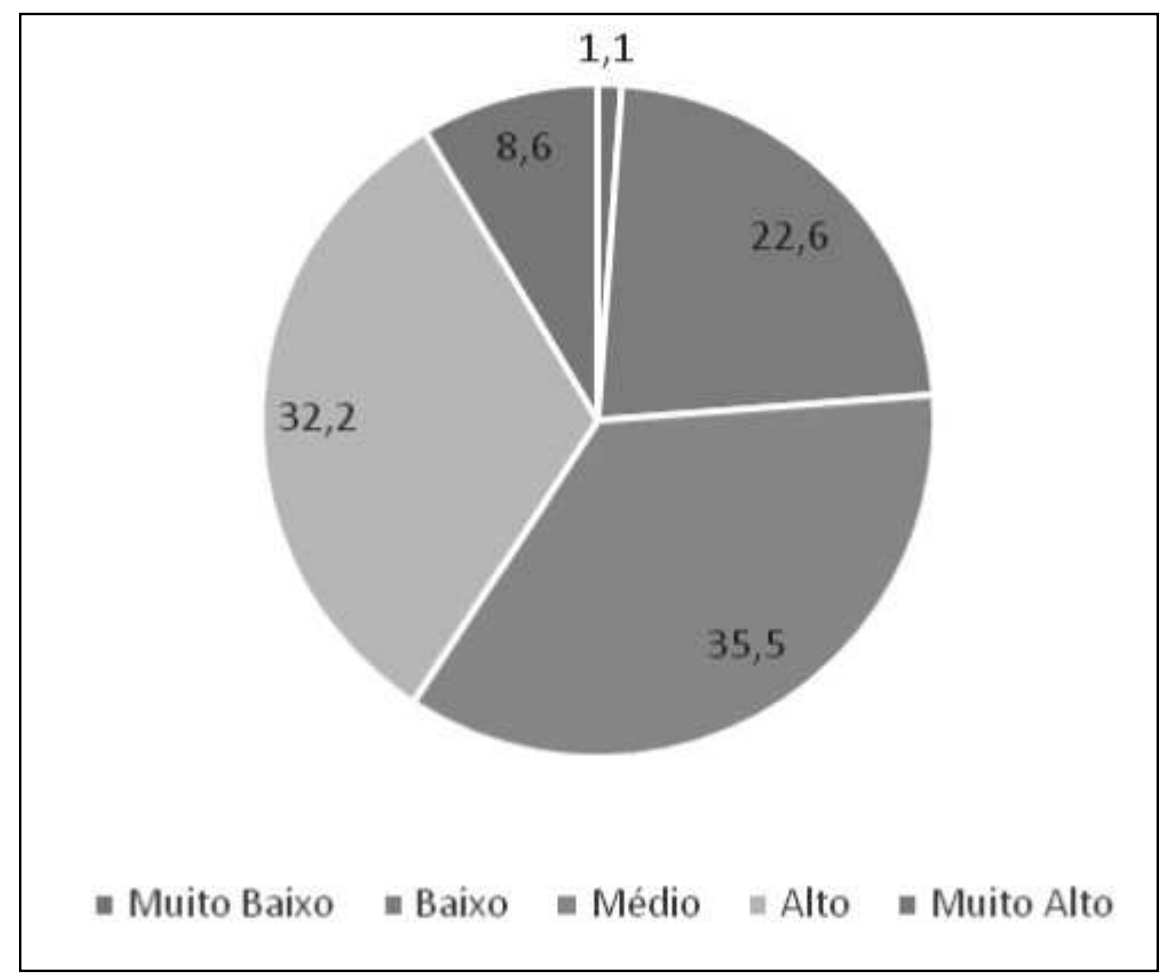

Fonte: Censo demográfico, IBGE -2010. Observatório das Metrópoles. Elaboração própria.

Apesar de as desigualdades urbanas se apresentarem como uma marca para o conjunto das 15 principais metrópoles do país, há diferenças expressivas entre essas metrópoles (tabela 1). As metrópoles com as melhores condições de bem-estar urbano, ao considerar aquelas que mais de $50 \%$ de sua população encontram-se em condições adequadas de bem-estar urbano (alto e muito alto), são Campinas (85,9\%), Porto Alegre (57,3\%), Belo Horizonte (56,4\%), Curitiba (55,5\%), Grande Vitória $(51,4 \%)$ e Goiânia $(50,9 \%)$, ilustradas na Figura $1^{5}$. Nota-se, ainda, que

\footnotetext{
${ }^{5}$ Como são 15 metrópoles brasileiras, consideradas neste trabalho, não será possível demonstrar as condições de bem-estar urbano de todas elas, por isso a opção para ilustração de algumas delas entre cada uma das situações analisadas.
} 
dessas metrópoles, somente Curitiba apresenta participação de pessoas que moram em nível muito baixo de bem-estar urbano $(0,5 \%)$, todas as outras não apresentam participação nesse nível inferior de bem-estar urbano. Poderíamos, portanto, dizer que são as metrópoles que apresentam as melhores condições urbanas do país, tendo em vista que a maior parte de sua população usufrui de condições adequadas de bem-estar urbano. Ainda que parcela da população não obtenha as condições adequadas, é expressivo também em todas elas o contingente de pessoas que moram em áreas de bem-estar urbano de nível médio.

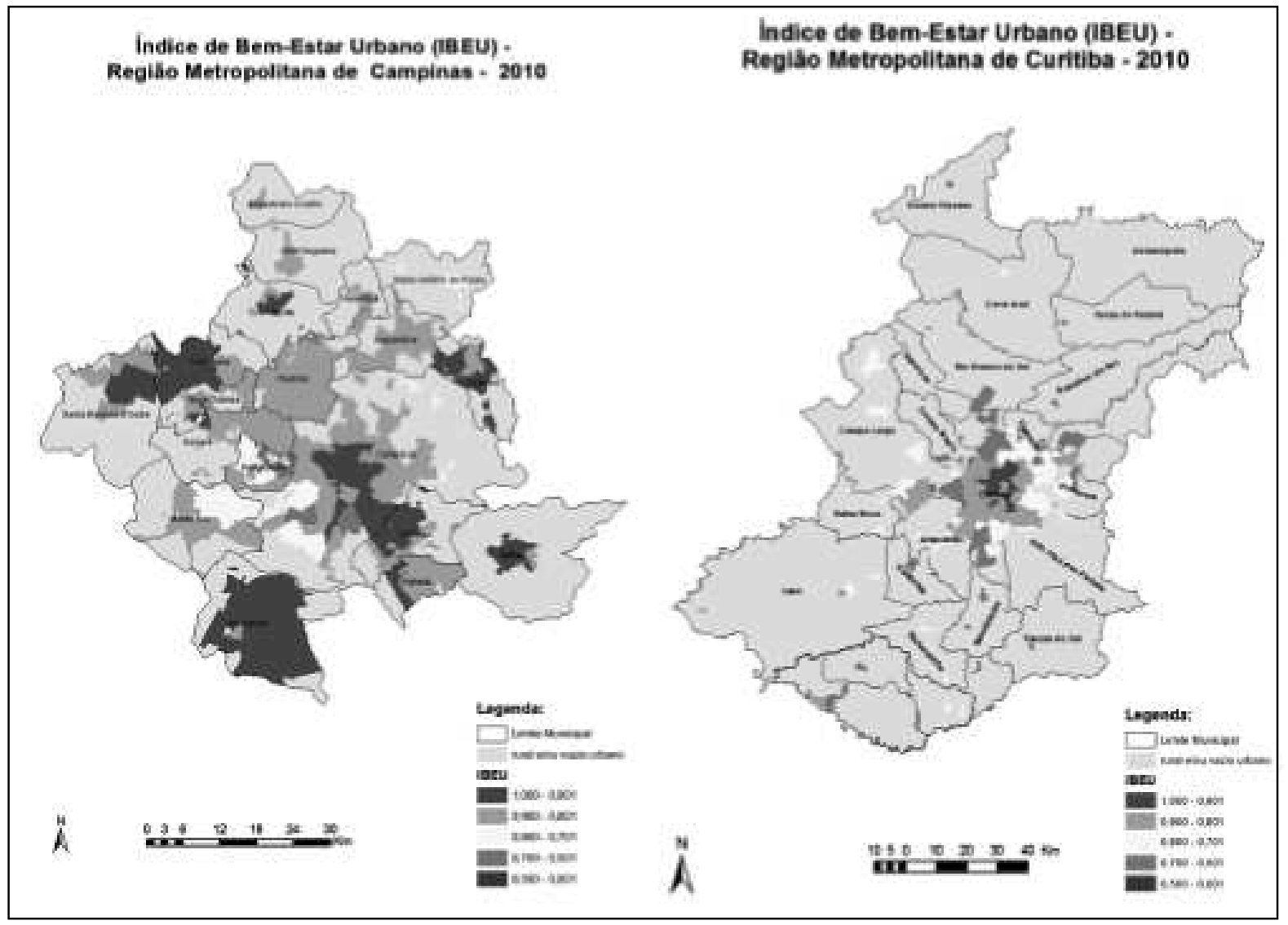

Figura 1. Ilustração de metrópoles com melhores condições de bem-estar urbano Fonte: Censo demográfico, IBGE -2010. Observatório das Metrópoles. 
Em condições opostas, ao considerar as metrópoles cuja maior parcela da população encontra-se em condições inadequadas de bem-estar urbano (baixo e muito baixo), estão Belém (80,5\%), Manaus (56,8\%) e Recife (55,7\%), ilustrada na Figura 2. Dessas metrópoles, somente Recife apresenta participação de pessoas em nível muito alto de bem-estar urbano (2,1\%). Com exceção de Belém, que concentra um contingente expressivo de pessoas em condições inadequadas, as demais metrópoles - Manaus e Recife - apresentam também contingente elevado de pessoas que moram em áreas de nível médio de bem-estar urbano. Essas são, portanto, as metrópoles que apresentam as piores condições de bem-estar urbano do país. Ainda assim, é significativa a diferença entre elas, pois entre as piores metrópoles em termos de bem-estar urbano, Belém apresenta situação muito mais dramática que as outras duas metrópoles, sendo, portanto, a metrópole com a condição mais grave em termos de bem-estar urbano do Brasil. 


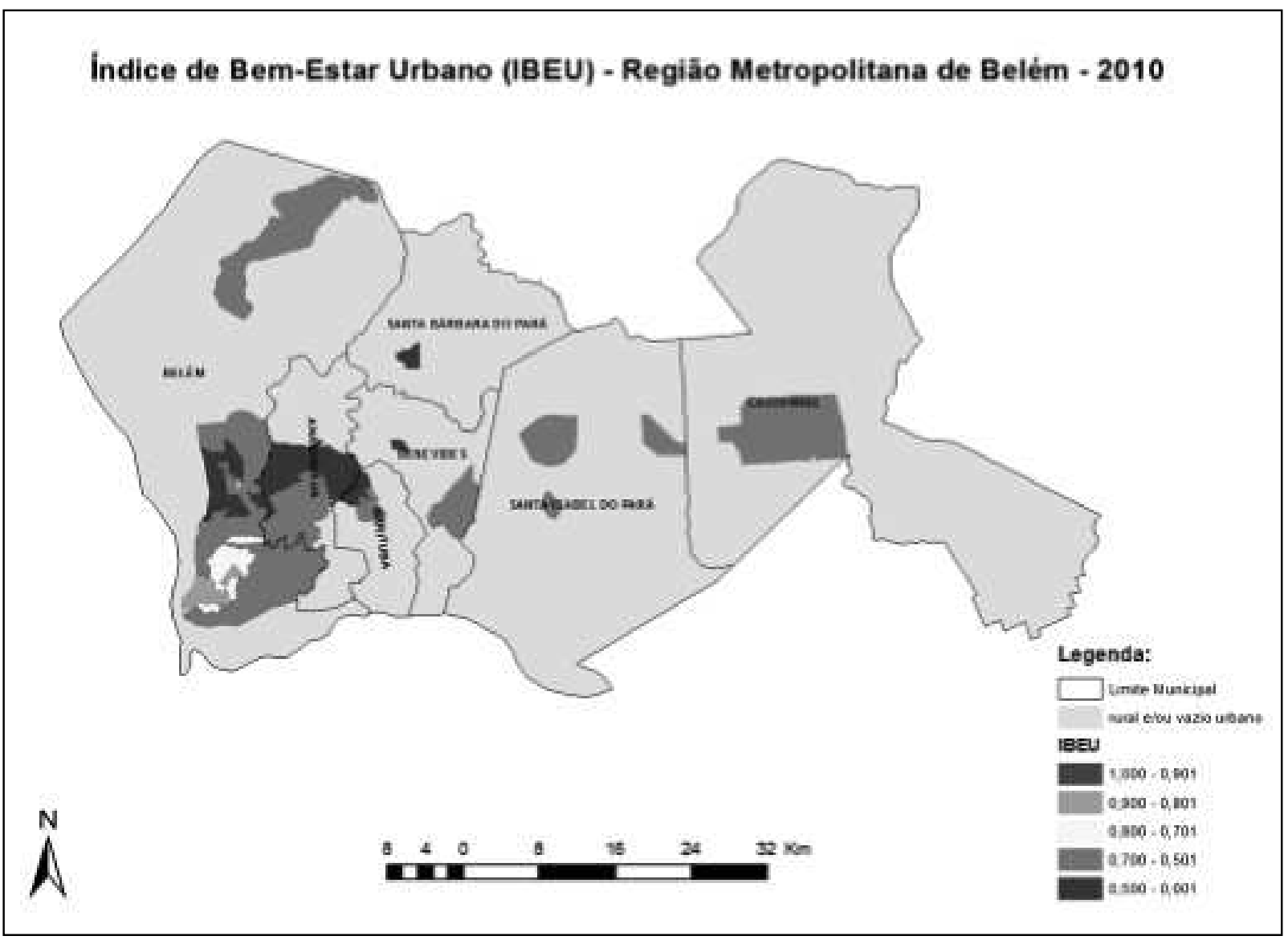

Figura 2. Ilustração de metrópoles com piores condições de bem-estar urbano Fonte: Censo demográfico, IBGE -2010. Observatório das Metrópoles.

Em condições intermediárias estão metrópoles cuja maior parcela da população encontra-se em áreas cujo nível de bem-estar urbano é considerado médio, como Florianópolis (52,5\%), Salvador (50,4\%) e Fortaleza (50,2\%), ilustradas na Figura 3, e metrópoles que há maior distribuição de pessoas entre os variados níveis de bem-estar urbano, sem que haja concentração em qualquer um deles, como são as metrópoles de São Paulo, RIDE-DF e Rio de Janeiro. Em relação às três metrópoles do primeiro grupo intermediário, podemos observar que Salvador $(25,7 \%)$ e Fortaleza $(25,4 \%)$ também apresentam contingente expressivo nos níveis inadequados de bem-estar urbano. Ao contrário, Florianópolis apresenta contingente expressivo em nível adequado (36,3\%). 


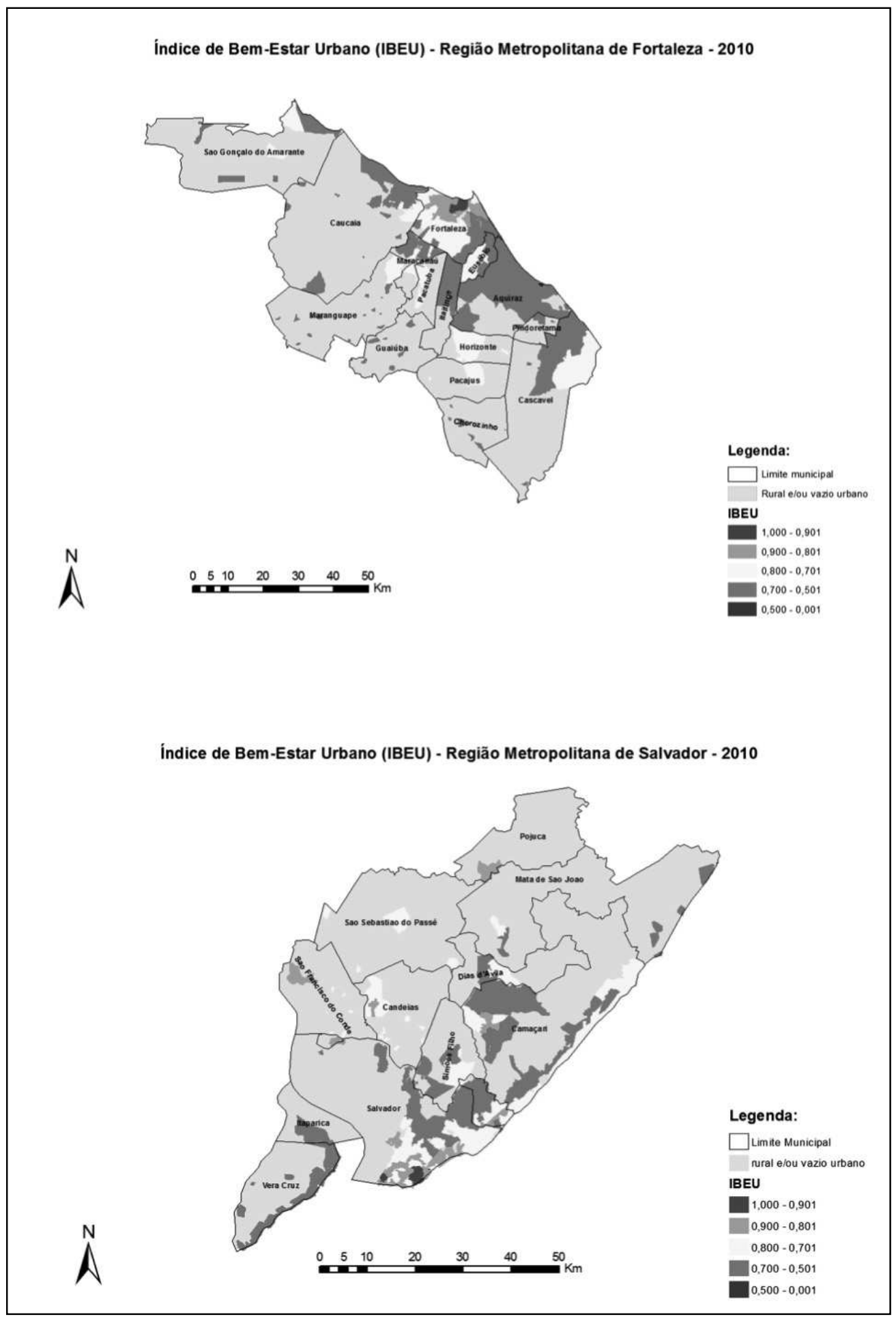

Figura 3. Ilustração de metrópoles com condições médias de bem-estar urbano Fonte: Censo demográfico, IBGE -2010. Observatório das Metrópoles. 


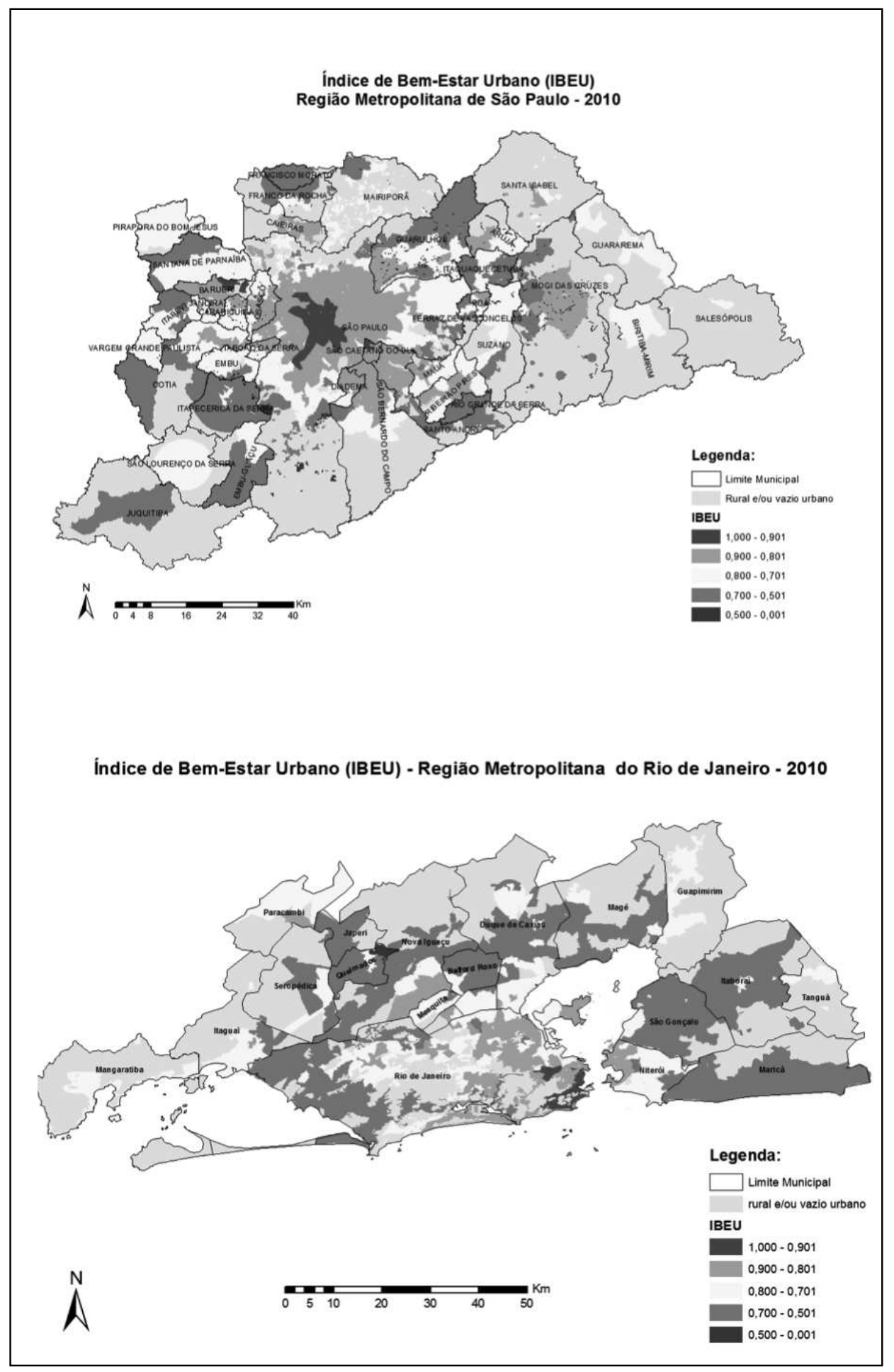

Figura 4. Ilustração de metrópoles com condições diversificadas de bem-estar urbano Fonte: Censo demográfico, IBGE -2010. Observatório das Metrópoles. 
Sociologias, Porto Alegre, ano 18, no 42, mai/ago 2016, p. 198-230

Tabela 1. Comparativo do nível do IBEU entre as metrópoles brasileiras - 2010

\begin{tabular}{|c|c|c|c|c|}
\hline Nível do IBEU & Manaus & Belém & Fortaleza & Recife \\
\hline Muito Baixo & 2,5 & 22,9 & - & 0,4 \\
\hline Baixo & 54,3 & 57,7 & 25,4 & 55,3 \\
\hline Médio & 37,5 & 12,4 & 50,2 & 31,0 \\
\hline Alto & 5,8 & 7,1 & 20,3 & 11,1 \\
\hline Muito Alto & - & - & 4,2 & 2,1 \\
\hline Total & 100,0 & 100,0 & 100,0 & 100,0 \\
\hline
\end{tabular}

\begin{tabular}{l|c|c|c|c}
\hline Nível do IBEU & Salvador & Belo Horizonte & Grande Vitória & Rio de Janeiro \\
\hline Muito Baixo & - & - & - & \\
\hline Baixo & 25,7 & 14,1 & 20,7 & 0,5 \\
\hline Médio & 50,4 & 29,5 & 27,9 & 31,4 \\
\hline Alto & 20,6 & 44,6 & 41,5 & 33,7 \\
\hline Muito Alto & 3,3 & 11,8 & 10,0 & 28,5 \\
\hdashline Total & 100,0 & 100,0 & 100,0 & 5,8 \\
\hline
\end{tabular}

\begin{tabular}{|c|c|c|c|c|}
\hline Nível do IBEU & Campinas & São Paulo & Curitiba & Florianópolis \\
\hline Muito Baixo & - & 0,5 & 0,5 & - \\
\hline Baixo & 5,5 & 12,6 & 14,4 & 11,3 \\
\hline Médio & 8,5 & 41,1 & 29,6 & 52,5 \\
\hline Alto & 46,8 & 40,0 & 38,8 & 32,3 \\
\hline Muito Alto & 39,1 & 5,8 & 16,7 & 4,0 \\
\hline Total & 100,0 & 100,0 & 100,0 & 100,0 \\
\hline
\end{tabular}

continua... 
continuação

\begin{tabular}{|c|c|c|c|c|}
\hline Nível do IBEU & Porto Alegre & Goiânia & RIDE-DF & Total \\
\hline Muito Baixo & - & - & 1,7 & 1,1 \\
\hline Baixo & 9,7 & 16,6 & 24,4 & 22,6 \\
\hline Médio & 33,0 & 32,6 & 35,5 & 35,5 \\
\hline Alto & 44,7 & 26,2 & 28,5 & 32,2 \\
\hline Muito Alto & 12,6 & 24,6 & 9,9 & 8,6 \\
\hline Total & 100,0 & 100,0 & 100,0 & 100,0 \\
\hline
\end{tabular}

Fonte: Censo demográfico - IBGE, 2010. Observatório das Metrópoles. Elaboração própria.

Quando se consideram as outras metrópoles, que há maior distribuição entre os níveis de bem-estar urbano, podemos observar que São Paulo, além de apresentar 41,1\% de pessoas em condições médias, apresenta 45,8\% de pessoas em condições adequadas de bem-estar urbano. Somente $13,1 \%$ das pessoas na metrópole paulista estão em condições inadequadas, apesar de em termos absolutos (2.582.552) corresponder a uma metrópole quase do tamanho de Campinas ou maior que as metrópoles de Belém, Manaus ou Goiânia. O mesmo não se verifica na RIDE-DF, pois 35,5\% estão em condições médias, 38,3\% em condições adequadas e $26,1 \%$ em condições inadequadas. O Rio de Janeiro apresenta situação que mais se aproxima do perfil das condições urbanas do conjunto das 15 metrópoles brasileiras, tendo em vista que 33,7\% das pessoas estão em condições médias, 34,4\% em condições adequadas e 31,9\% em condições inadequadas. O contingente em condições inadequadas da metrópole do Rio de Janeiro (3.790.541) é maior que a metrópole de Curitiba, de Fortaleza, de Recife ou de Salvador.

Por meio da análise de conjunto das 15 principais metrópoles brasileiras, podemos considerar que as desigualdades urbanas observadas nos 
espaços intrametropolitanos é uma realidade nacional, tendo em vista que quase um quarto das pessoas moram em áreas que apresentam condições inadequadas de bem-estar urbano. Por outro lado, pudemos observar também que apesar de ser uma realidade nacional, essas desigualdades se configuram de modo distinto entre as 15 metrópoles, pois há metrópoles com situações mais satisfatórias nas suas condições de bem-estar urbano, tendo em vista a maior parcela da população encontra-se em áreas de condições adequadas ou médias de bem-estar urbano; há metrópoles com situações precárias nas suas condições urbanas, pois a maior parcela da população encontra-se em condições inadequadas de bem-estar urbano; há metrópoles em situações intermediárias, ou por concentrar a maior parcela da população em nível médio de bem-estar urbano ou por haver maior distribuição populacional entre os diferentes níveis de bem-estar urbano.

As desigualdades urbanas se manifestam quando apenas uma parcela da população é capaz de usufruir das condições urbanas necessárias para assegurar o bem-estar urbano e, por meio disso, assegurar a sua reprodução social, enquanto outras pessoas não conseguem acessar à totalidade das condições urbanas necessárias para garantir o bem-estar urbano condizente com as necessidades para assegurar a reprodução social. Apesar das diferenças que vimos entre as metrópoles, em todas elas há pessoas ou grupo de pessoas que conseguem obter os benefícios urbanos que asseguram bem-estar, enquanto outros grupos são incapazes de acessá-los em sua plenitude. O perfil socioeconômico desses grupos é o que será detalhado para o conjunto das metrópoles na próxima seção. 


\section{Desigualdades urbanas e desigualdades sociais}

A análise do perfil socioeconômico segundo os níveis de bem-estar urbano permite revelar quais são os grupos sociais que se apropriam dos recursos coletivos urbanos. Na medida em que há desigualdades urbanas dentro das principais metrópoles brasileiras, o que se coloca como questão fundamental é saber quem são os grupos sociais que se beneficiam da distribuição desigual desses recursos. Isso porque, a depender do tipo de correspondência existente entre os grupos sociais que se beneficiam dos recursos coletivos urbanos, poderemos analisar a existência de distribuição mais ou menos igualitária desses recursos. A distribuição mais igualitária significa que os recursos coletivos não estariam relacionados ao perfil socioeconômico da população, sendo distribuídos de maneira mais ou menos homogênea entre os diferentes grupos sociais. O contrário ocorreria em distribuição desigual, pois determinados grupos sociais teriam mais acesso aos recursos coletivos em detrimento de outros. Para avaliar o perfil socioeconômico da população do conjunto das 15 principais metrópoles, vamos analisar os dados segundo a característica de cor ou raça, escolaridade, rendimento e posição social segundo algumas categorias sócio-ocupacionais selecionadas.

Como tradicionalmente é observado no Brasil, há diferenças no acesso aos recursos societários de acordo com a cor ou raça da população em favor das pessoas de cor branca, o que pode decorrer dos mecanismos de discriminação racial existente na sociedade. Para realizar essa verificação, vamos avaliar o relacionamento entre a variável cor (pessoas brancas e pessoas não-brancas) e o nível de bem-estar urbano, conforme o gráfico 2. Nesse gráfico, constatamos que nas áreas das metrópoles que se caracterizam como sendo espaços muito alto de bem-estar urbano $78,9 \%$ da população são de cor branca, somente $21,1 \%$ são de cor não-brancas (pretas e pardas). Nas áreas consideradas de bem-estar urbano 
alto, 60,9\% das pessoas são de cor branca e 39,1\% de cor não-branca. Nas áreas em condições médias de bem-estar urbano, há predomínio de pessoas de cor não-branca, com 55,9\%, ao passo que $44,1 \%$ são pessoas de cor branca. Nas áreas consideradas baixo e muito baixo em termos de bem-estar urbano prevalecem pessoas de cor não-branca, nas primeiras há $65,3 \%$ e nas segundas $73,8 \%$. O tipo de relacionamento observado, portanto, entre a variável cor e o nível do bem-estar urbano é que há uma nítida correspondência dessas variáveis no sentido de que os espaços melhores providos das condições urbanas de bem-estar são aqueles apropriados em sua maioria pelos grupos de pessoas de cor branca. $\mathrm{Na}$ medida em que os espaços passam a se caracterizar pela ausência de recursos coletivos urbanos, aumenta a proporção de pessoas de cor não-branca e, por conseguinte, se reduz a de pessoas de cor branca. A partir desta constatação podemos inferir que a cor da pele das pessoas pode ser utilizada como mecanismo de acesso aos recursos coletivos urbanos, o que demonstra que as desigualdades urbanas refletem também as desigualdades raciais ou, dito de outra forma, as desigualdades raciais são reproduzidas no acesso desigual aos recursos coletivos urbanos. 
Gráfico 2. Nível do IBEU das 15 principais regiões metropolitas do Brasil segundo grupo de cor das pessoas - 2010

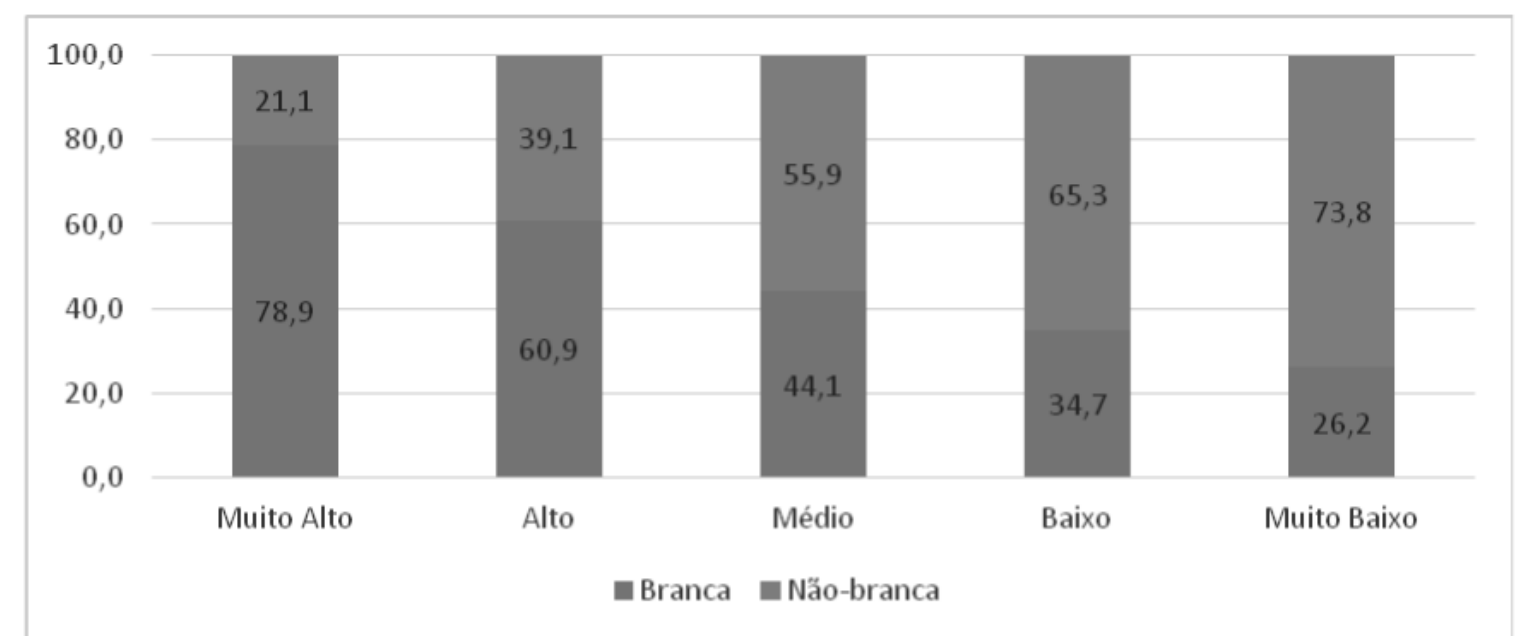

Fonte: Censo demográfico, IBGE -2010. Observatório das Metrópoles. Elaboração própria.

A análise do IBEU por meio da variável escolaridade possibilita a avaliação das desigualdades urbanas segundo um atributo adquirido e, portanto, uma variável que também se caracteriza como um recurso socialmente distribuído em uma determinada coletividade. Porém, um recurso que a rigor todos teriam condições de acessá-lo. Tendo em vista essas considerações, relacionamos o IBEU segundo a proporção de pessoas de 25 anos e mais de idade com nível superior, pois essa seria uma idade em que as pessoas já poderiam ter obtido esse nível de instrução. Como podemos observar no gráfico 3, quase a metade da população acima de 25 anos de idade possui nível superior nas áreas onde o IBEU apresenta as melhores condições (nível muito alto), na medida em que reduz o nível das condições urbanas se reduz também a proporção de pessoas com nível superior, sendo que no pior nível do IBEU há apenas 2,9\% com nível superior de escolaridade. Essas constatações sugerem que há certo relacionamento entre as desigualdades urbanas e as desigualdades educacionais. E isso nos levar a considerar que os grupos sociais que conseguem 
se apropriar dos recursos escolares também são aqueles que se apropriam dos recursos coletivos urbanos.

Gráfico 3. Nível do IBEU das 15 principais regiões metropolitas do Brasil segundo proporção de pessoas de 25 anos ou mais de idade com nível superior de escolaridade - 2010 (em \%)

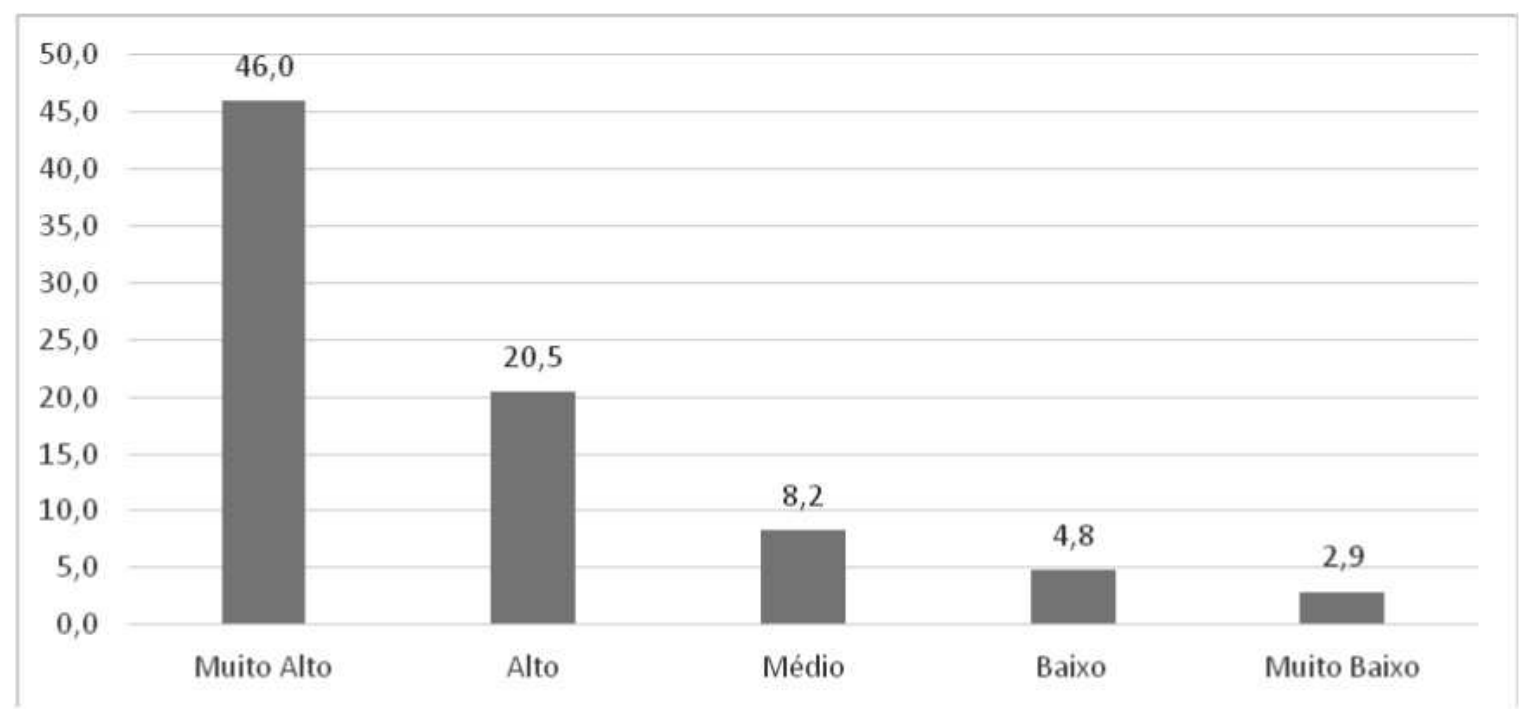

Fonte: Censo demográfico, IBGE -2010. Observatório das Metrópoles. Elaboração própria

O mesmo tipo de avaliação pode ser feito em relação ao nível de rendimento das pessoas. Observamos que há uma nítida correspondência também entre o nível de bem-estar urbano e o rendimento médio da população, na medida em que as áreas que apresentam os níveis mais elevados de bem-estar urbano são aquelas onde moram também as pessoas que apresentam - em média - maiores rendimentos, como pode ser visto no gráfico 4. Por outro lado, nas áreas onde as condições urbanas são piores se caracterizam por apresentar população com média de rendimento menor. Para se ter uma ideia das desigualdades de renda segundo os níveis de bem-estar urbano, podemos observar que as pessoas que moram nas áreas de melhores condições urbanas ganham, em média, 7,3 vezes mais que a média do rendimento das pessoas que moram nas áreas onde se apresentam as piores condições urbanas. 
Gráfico 4. Nível do IBEU das 15 principais regiões metropolitas do Brasil segundo rendimento médio mensal - 2010

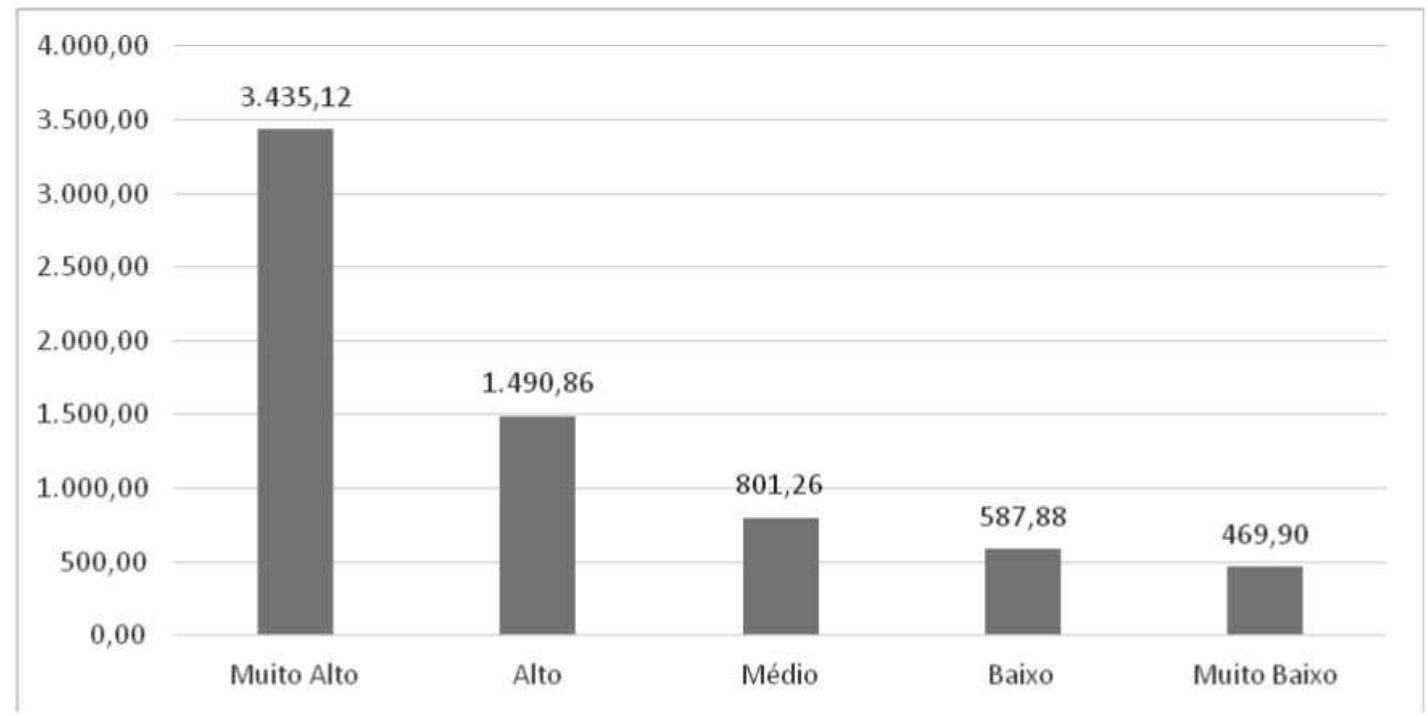

Fonte: Censo demográfico, IBGE -2010. Observatório das Metrópoles. Elaboração própria.

Outra forma de perceber as diferenças de rendimento entre as áreas intrametropolitanas segundo o nível de bem-estar urbano é analisar a proporção de pessoas que ganham até dois salários mínimos em cada um dos contextos urbanos. Como podemos observar no gráfico 5, quanto melhor o nível de bem-estar urbano menor é a proporção de pessoas que ganham até dois salários mínimos. Nas áreas das metrópoles classificadas como de nível muito alto de bem-estar urbano, há $47,1 \%$ de pessoas que auferem aquele patamar de rendimento mensal; por outro lado, nas áreas onde apresenta o pior nível de bem-estar urbano, 90,6\% das pessoas ganham até dois salários mínimos, quase a totalidade das pessoas nesses contextos ganham até dois salários mínimos. Ou seja, as desigualdades urbanas refletem, por sua vez, as desigualdades de renda. 
Gráfico 5. Nível do IBEU das 15 principais regiões metropolitas do Brasil segundo proporção de pessoas que recebem até dois salários mínimos - 2010 (em \%)

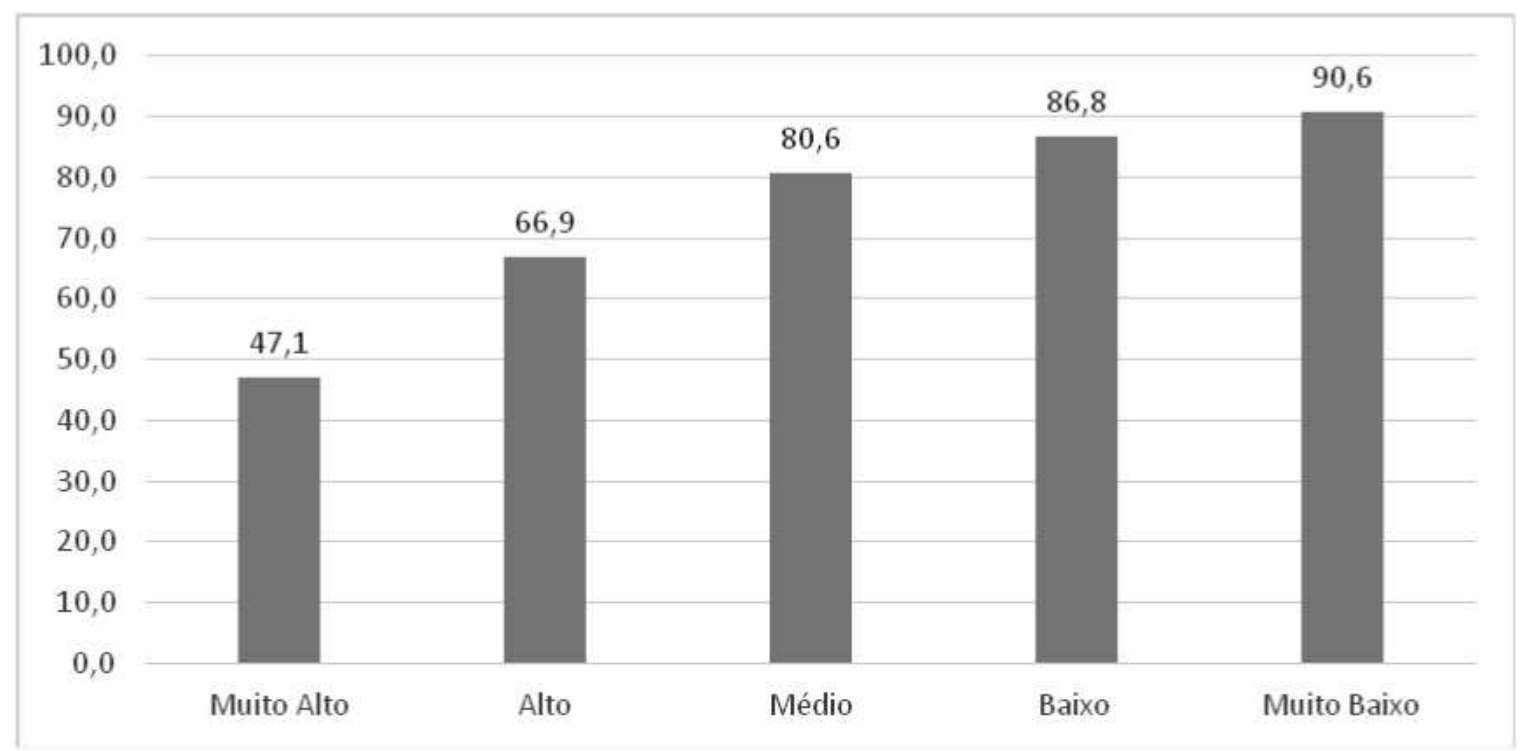

Fonte: Censo demográfico, IBGE -2010. Observatório das Metrópoles. Elaboração própria.

Outra forma de avaliação das condições sociais da população e das condições urbanas é por meio do relacionamento do IBEU com a posição social dos indivíduos, observada através de um esquema de estratificação social, construído a partir da variável ocupação ${ }^{6}$. A utilização da posição social construida dessa maneira tem inspiração em diversas correntes de pensamento sociológico quando procuram compreender o modo de organização social, considerado como divisão social do trabalho (Davis; Moore, 1977) ou estrutura social (Weber, 1977; Stavanhagen, 1977) ou ainda como espaço social (Bourdieu, 2008), a depender da perspectiva teórica utilizada em sua operacionalização empírica (Crompton, 1993).

\footnotetext{
${ }^{6}$ Neste trabalho, vamos utilizar a posição social construída pelo Observatório das Metrópoles, a partir de um esquema de estratificação social hierárquico considerado proxy da estrutura social, por meio da teoria de espaço social de Pierre Bourdieu (Ribeiro; Ribeiro, 2013b).
} 
Para melhor ilustração das diferenças entre as condições urbanas segundo a posição social dos indivíduos, apresentamos no gráfico 6 o nível de bem-estar urbano para as categorias Dirigentes e Profissionais de Nível Superior, que correspondem as posições mais elevadas da hierarquia social, e para os Trabalhadores Manuais, que correspondem a junção dos trabalhadores do terciário especializado e não-especializado, trabalhadores do secundário e trabalhadores agrícolas. Podemos observar que nos níveis de bem-estar urbano mais elevado há maior proporção de pessoas que ocupam as posições mais elevadas da estrutura social (dirigentes + profissionais), essa proporção se reduz para os níveis de bem-estar urbano mais baixos. O contrário é observado quando se consideram os trabalhadores manuais, pois sua proporção é maior nos piores níveis de bem-estar urbano; reduz essa proporação a medida que se eleva o nível de bem-estar urbano. Ao considerar as posições sociais como construídas hierarquicamente, podemos perceber que aqueles grupos sociais que ocupam as posições mais elevadas são os que se apropriam das melhores condições urbanas de vida. Isso leva à constatação de que as desigualdades de posição social também se expressam territorialmente. 
Gráfico 6. Nível do IBEU das 15 principais regiões metropolitas do Brasil segundo posições sociais selecionadas - 2010 (em \%)

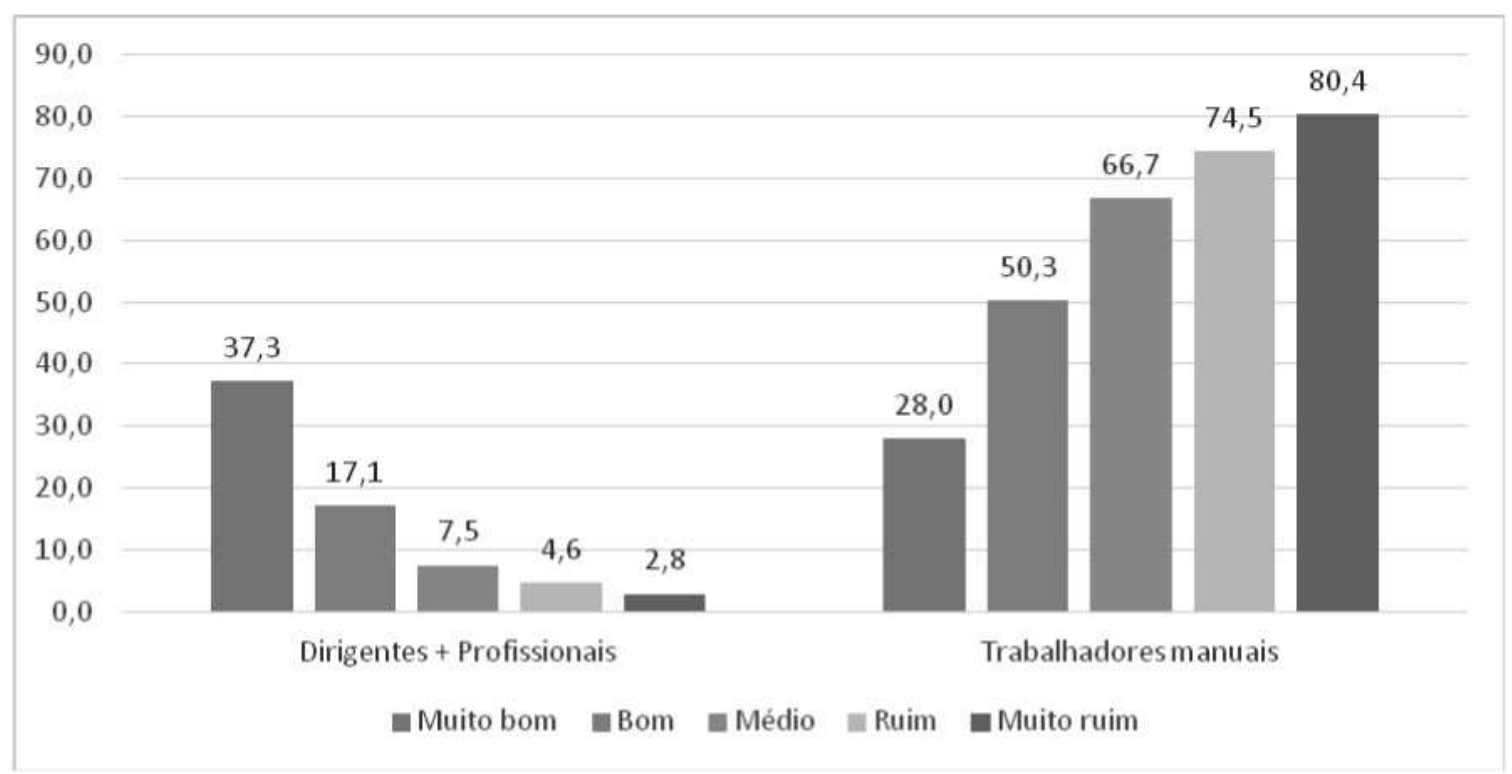

Fonte: Censo demográfico, IBGE -2010. Observatório das Metrópoles. Elaboração própria.

\section{Em busca de explicação}

As desigualdades urbanas, como pudemos observar na seção anterior, apresenta relacionamento com todas as dimensões das desigualdades sociais analisadas, como as desigualdades raciais, as desigualdades educacionais, as desigualdades de renda e também com as desigualdades de posição social. Ao realizar tais constatações, a questão que se coloca é: como podemos explicar os mecanismos que permitem a existência desses relacionamentos? Essa é uma questão que apresenta elevado nível de dificuldade, por demonstrar desafios metodológicos que sejam suficientemente operacionalizados de modo a encontrar respaldo nas abordagens teóricas. Apesar de não sermos capazes de responder de modo satisfatório à questão apresentada, vamos procurar, pelo menos, apresentar algumas especulações acerca das dificuldades que se colocam como uma pedra no meio do caminho. 
Há que considerar que todas as dimensões das desigualdades que foram relacionadas com as condições de bem-estar urbano também apresentam relacionamento entre si. As desigualdades raciais também se manifestam em relação à escolaridade, à renda e à posição social. As desigualdades educacionais também apresentam relação com as desigualdades de renda. Assim como, as desigualdades de renda também se relacionam com as desigualdades de posição social. Isto é, se todas essas dimensões estão relacionadas, uma primeira questão a ser enfrentada é a de saber qual o sentindo da causalidade existente entre essas variáveis. E, por meio disso, saber qual o sentido da causalidade quando se considera também as desigualdades de bem-estar urbano.

Poderíamos considerar, porém, que há múltiplas determinações das desigualdades urbanas, quando se considera o perfil socioeconômico dos grupos sociais. Apesar disso, há evidências suficientes para permitir-nos considerar que essas múltiplas determinações não necessariamente têm efeito direto sobre as desigualdades urbanas. Algumas delas podem impactar indiretamente por meio de mediações exercidas por outras variáveis. Ao considerar as variáveis que estamos observando, podemos supor que o nível de escolaridade dos indivíduos seja importante para o alcance de sua posição social, tendo em vista que estamos considerando a posição social decorrente de uma agregação de ocupações. O que quer dizer que para acessar determinadas posições sociais torna-se necessário o alcance de níveis de escolaridade requeridos pela ocupação, o que nos faz crer que haja causalidade entre essas duas variáveis no sentido de a escolaridade ser explicativa da posição social. Do mesmo modo, podemos supor que há diferenças de obtenção de rendimento a depender da posição social que os indivíduos alcançam. Nesse sentido, o nível de rendimento é determinado pela posição social e, indiretamente, pela escolaridade dos indivíduos (Ribeiro, 2012). Se o rendi- 
mento é importante para acessar áreas da cidade melhor providas dos bens coletivos urbanos, então poderíamos supor que as desigualdades urbanas decorrem diretamente do nível de rendimento dos indivíduos e indiretamente da posição social e, por sua vez, da escolaridade. Nesse modelo teórico, as desigualdades raciais podem se manifestar tanto em relação à escolaridade, à posição social, às diferenças de renda dos indivíduos e às desigualdades urbanas, propriamente ditas. Mas podem também se manifestar em todas essas dimensões.

Mas poderíamos considerar, também, que quando os indivíduos conseguem acessar áreas da cidade melhor providas dos recursos coletivos urbanos, eles terão também condições de ter melhor acesso à escolaridade, às ocupações que correspondam posições sociais mais elevadas da estrutura social e mesmo a melhor nível de renda. O contrário ocorreria quando os indivíduos acessam às áreas com as piores condições urbanas. Também, nestes casos, o modo como se realizam essas determinações podem ser diretas ou indiretamente. Seja no sentido de o bem-estar urbano exercer efeito direto tanto sobre a escolaridade, quanto sobre a posição social e também sobre o nível de renda; seja no sentido desse efeito ser exercido indiretamente, o que poderia ser compreendido apenas ao longo da trajetória dos indivíduos, o que exigiria, portanto, análise longitudinal para apreensão desses relacionamentos. De qualquer modo, independentemente de as determinações serem diretas ou indiretas, um tipo de análise como essa requer que seja elucidado quais são os mecanismos que tornam as desigualdades urbanas importantes na explicação de outras modalidades de desigualdade social.

Independentemente do sentido da causalidade existente entre as desigualdades urbanas e as diversas dimensões das desigualdades sociais e dos mecanismos explicativos do modo como o relacionamento entre essas dimensões se realizam, é importante considerar que os dados apre- 
sentados na seção anterior demonstram a existência dos fenômenos de diferenciação e segmentação socioespaciais nas principais metrópoles brasileiras, capazes de gerar segregação socioespacial (Kaztman, 2012). O fenômeno da diferenciação socioespacial se manifesta por haver no interior das metrópoles áreas que concentram, ao mesmo tempo, os recursos coletivos urbanos, as pessoas com mais elevado nível de escolaridade, com maior nível de renda, que ocupam as posições mais elevadas da estrutura social e predominantemente de cor branca. Ao passo que nas áreas mais desprovidas dos recursos coletivos urbanos são também aquelas que concentram as pessoas com menor nível de escolaridade, com menor nível de renda, que ocupam posições mais inferiores da estrutura social e são em sua maioria de cor não-branca. Entre um polo e outro das áreas da metrópole, há um contínuo, onde se mesclam essas condições urbanas e sociais. Como essas áreas se diferenciam pelos recursos existentes e pelo perfil socioeconômico dos seus moradores, há maior dificuldade em haver interação entre os diferentes grupos sociais por se localizarem em contextos espaciais distintos, denotando o fenômeno da segmentação socioespacial. Na medida em que esses fenômenos se manifestam, há grande probabilidade da existência da segregação socioespacial, pois os grupos sociais ao se diferenciarem nas diferentes áreas do espaço urbano e, por este motivo, por haver baixa ou ausência de interação, tendem a criar barreiras que os separam uns dos outros, tendo como resultado a fratura do tecido social da cidade. A consequência é a perda de disposição de seus habitantes para cooperação, a resolução pacífica de conflitos e a reivindicação de direitos para toda a coletividade (Kaztman, 2012). Ao mesmo tempo, tendem a realizar reivindicação ou exercer pressão sobre o poder público para o grupo social que se reconhece e é integrante, e não para outros grupos sociais com os quais não possuem interação. A experiência mostra que aqueles grupos sociais que apresentam melhor 
condições urbanas e sociais são também os que têm maior poder de reivindicação do poder público. Num contexto como esse, os fenômenos da diferenciação, segmentação e segregação socioespaciais reproduzem as desigualdades urbanas e, por conseguinte, as condições desiguais de reprodução social.

$\mathrm{Na}$ medida em que esses fenômenos operam, a distribuição da Renda Real, na perspectiva de David Harvey (1973), torna-se ainda mais desigual para os grupos sociais que se localizam em diferentes contextos territoriais. Isso ocorre, porque a distribuição dos recursos coletivos urbanos, importantes para reprodução social, valoriza as áreas no interior da metrópole onde eles são realizados, aumentando assim o nível de renda real dos grupos sociais que se beneficiam desses recursos, por meio de mudanças que ocorrem no sistema de preço do solo urbano. Por decorrência disso, fica certamente mais difícil para outros grupos sociais poderem se localizar nos espaços providos das melhores condições urbanas, demonstrando barreiras à entrada de grupos sociais distintos. A medida que isso acontece as áreas ocupadas pelos grupos sociais de alto rendimento fazem elevar o seu status social, o que colabora para que tais grupos tenham também maior poder político para realizar reivindicações do Estado, contribuindo para um processo de causação circular sempre em benefícios dos grupos sociais providos das melhores condições de bem-estar urbano (Vetter et al, 1981).

\section{Considerações finais}

Mesmo tendo passado mais de três décadas da emergência da questão urbana no Brasil, vimos, ao longo deste trabalho, que as desigualdades urbanas continuam sendo uma realidade nacional das metrópoles do país, tendo em vista as diferenças intraurbanas referente ao bem-estar 
urbano. Porém, a manifestação das desigualdades urbanas se apresenta de modo diferente entre elas. Há metrópoles em que a maior parcela da população usufrui de condições urbanas adequadas (Campinas, Porto Alegre, Belo Horizonte, Curitiba, Grande Vitória e Goiânia); há metrópoles em que, ao contrário, maior parcela da população vive em condições inadequadas de bem-estar urbano (Belém, Manaus e Recife); há também outras metrópoles em que a maior parcela da população vive em condições médias de bem-estar urbano (Florianópolis, Salvador e Fortaleza); e ainda metrópoles em que não prevalece nenhum nível de bem-estar urbano (São Paulo, RIDE-DF e Rio de Janeiro).

Foi observado também que as áreas do interior das metrópoles que apresentam as melhores condições de bem-estar urbano são também aquelas cuja composição social predomina pessoas de maior nível de rendimento, nível de escolaridade mais elevado, são de cor branca e ocupam posições sociais mais elevadas da estrutura social. O contrário ocorre nas áreas das metrópoles onde prevalece as piores condições de bem-estar urbano, tendo em vista que a composição social se configura por apresentar, proporcionalmente, pessoas com menor nível de rendimento, com menor escolaridade, de cor não-branca e que ocupam posições sociais mais inferiores da estrutura social. Na verdade, há um contínuo em termos de composição social entre as áreas que apresentam as melhores condições de bem-estar urbano e as áreas que apresentam as piores condições.

Apesar de haver relacionamento entre essas variáveis, coloca-se como importante desafio a compreensão dos mecanismos que operam no sentido de fazer com que os espaços que apresentam as melhores condições de bem-estar urbano são aqueles ocupados por grupos sociais que também apresentam as melhores condições sociais e vice-versa. Vimos, porém, que a existência de segregação socioespacial contribui para 
que essa situação seja reproduzida, tendo em vista que as diferenças territoriais ao contribuir para ausências de interação entre grupos sociais distintos, levam a incapacidade da construção de identidades coletivas e reivindicação de direitos para o conjunto da coletividade. E quando isso acontece, a ação coletiva ocorre somente no sentido reivindicação de recursos coletivos para o grupo de pertencimento, o que implica em disputas ou conflitos sociais em busca dos recursos coletivos urbanos. Como normalmente essas reivindicações são feitas para o poder público, este tende a beneficiar aqueles grupos sociais já providos das melhores condições urbanas, porque são também os que possuem maior poder de pressão frente ao aparelho do Estado e também porque a burocracia do aparelho de Estado é constituída pelos grupos sociais de posições sociais mais elevadas, o que contribui para um processo de causação circular da distribuição dos recursos públicos e, por conseguinte, para reprodução das desigualdades urbanas e desigualdades sociais.

A compreensão dessa dinâmica é fundamental para entender as desigualdades urbanas, quando esta é analisada por meio de um índice, como foi o caso do IBEU. No entanto, para avançar nesse entendimento, por um lado, torna-se importante relacionar os resultados aqui encontrados com o aprofundamento do comportamento das variáveis componentes desse índice, para observar inclusive como cada uma delas se comportam no interior das metrópoles, como elas estão relacionadas e quais dessas variáveis são mais explicativa das desigualdades urbanas existentes; por outro lado, torna-se relevante também aprofundar as políticas públicas nas esferas de governo responsáveis pela distribuição dos recursos coletivos urbanos, pois com isso será possível compreender como as desigualdades urbanas, mesmo sendo uma realidade nacional, apresentam diferenças importantes entre as metrópoles do país. 
Marcelo Gomes Ribeiro: Professor Adjunto do Instituto de Pesquisa e Planejamento Urbano e Regional (IPPUR) da Universidade Federal do Rio de Janeiro (UFRJ). Economista (PUC-GO), Mestre em Sociologia (UFG) e Doutor em Planejamento Urbano e Regional (UFRJ). Pesquisador do Observatório das Metrópoles. $\triangle$ marceloribeiro@ippur.ufrj.br.

\section{Referências}

1. BOURDIEU, P. A Distinção: Crítica social do julgamento. São Paulo: Edusp, Porto Alegre, RS: Zouk, 2008. 560 p.

2. CASTELLS, M. La urbanización dependiente em América Latina. In: CASTELLS, M. Imperialismo y urbanizacion em America Latina. Barcelona: Editorial Gustavo Gili, 1973, p. 7-26.

3. CROMPTON, R. Class and stratification. Cambridge, UK: Polity Press, 1993. $231 \mathrm{p}$.

4. DAVIS, K.; MOORE, W. E. Alguns pricipios de estratificação. In VELHO, O. G.; PALMEIRA, M. G. S.; BERTELLI, A. R. (Org.). Estrutura de Classe e Estratificação Social. Rio de Janeiro: Zahar Editores, 1977. p. 101-116.

5. HARVEY, D. Social Justice and the City. Baltimore, John Hopkins, 1973.

6. IANNI, Octávio. Estado e Planejamento no Brasil (1930-1970). Rio de Janeiro: Civilização Brasileira, 1971

7. KAZTMAN, R. Territorio y cohesión social en las grandes ciudades de América Latina. In: $3^{\circ}$ Encontro da Anpocs, 36., Águas de Lindóia, MG, 2012.

8. KOWARICK, L. A espoliação urbana. 2ª ed. Rio de Janeiro: Paz e Terra, 1993.

9. MARICATO, E. (org.). A produção da casa (e da cidade) no Brasil industrial. Petrópolis: Vozes, 1979.

10. OBSERVATÓRIO das Metrópoles. Análise das Regiões Metropolitanas do Brasil. Relatório da Atividade 1: identificação dos espaços metropolitanos e construção de tipologias. Rio de Janeiro, Observatório das Metrópoles, 2005.

11. OLIVEIRA, F. O Estado e o urbano no Brasil. In: Espaço e Debates, São Paulo: NERU/Cortez, n. 6, p. 36-54, 1982.

12. QUIJANO, A. La formación de um universo marginal en las ciudades de América Latina. In: CASTELLS, M. Imperialismo y urbanizacion em America Latina. Barcelona: Editorial Gustavo Gili, 1973, p. 141-166. 
13. RIBEIRO, L. C.; RIBEIRO, M. (orgs.). Ibeu: índice de bem-estar urbano. 1. ed. - Rio de Janeiro: Letra Capital, $2013 a$.

14. RIBEIRO, L.C.; RIBEIRO, M. Análise social do território: fundamentos teóricos e metodológicos. 1. ed. Rio de Janeiro: Letra Capital, 2013b. 76p

15. RIBEIRO, M. Educação, estrutura social e segmentação residencial do território metropolitano: Análise das Desigualdades de Renda do Trabalho em Regiões Metropolitanas do Brasil. (Tese de doutorado). Rio de Janeiro: UFRJ, 2012. 321p.

16. SINGER, P. Urbanização, dependência e marginalidade na América Latina. In: SINGER, P. Economia política da urbanização. 3a ed. São Paulo: Contexto, 2012.

17. STAVENHAGEN, Rodolfo. Estratificação Social e Estrutura de Classe. In: VELHO, O. G.; PALMEIRA, M. G. S.; BERTELLI, A. R. (Org.). Estrutura de Classe e Estratificação Social. Rio de Janeiro: Zahar Editores, 1977. p. 117-148.

18. VETTER, D. et. al. A proposição dos benefícios das ações do Estado em áreas urbanas: seus determinantes e análise através de ecologia fatorial. Revista Brasileira de Geografia. Rio de Janeiro, ano 43, n.0 4, p. 455-476, out./ dez. 1981.

19. WEBER, M. Classe, Status, Partido. In VELHO, O. G.; PALMEIRA, M. G. S.; BERTELLI, A. R. (Org.). Estrutura de Classe e Estratificação Social. Rio de Janeiro: Zahar Editores, 1977. p. 57-76.

Recebido em: 12/02/2016

Aceite Final: 12/04/2016 